\title{
COVID-19 Statement: The unanticipated costs of COVID-19 to South Africa's quadruple disease burden
}

As of early July 2020, the full force of COVID-19 has yet to strike in South Africa, though it has already impacted the economy further and disrupted the healthcare system. While much has been said about the former, with few exceptions, little has been discussed about the disruption to routine, essential healthcare services. The pandemic brings threats previously unknown and has reordered priorities for health. Hospitals have reprogrammed care units to accommodate COVID-19 patients, while others have temporarily closed ${ }^{1}$.

To date, government leadership has done a remarkable job of trying to limit the spread of SARS-CoV-2 infection by promoting the most effective prevention toolkit currently available - social-behavioural measures such as social distancing, handwashing and ensuring that transportation and workplaces apply safety protocols.

The health leadership of ASSAf believes, however, that government's leadership, response and guidance to the pandemic can be further strengthened by attending to the following concerns. It is crucial that the National Coronavirus Command Council, and the structures reporting to it, ensure that by focusing on COVID-19, we do not lose sight of the opportunity costs of shifting priorities. The advisory bodies need to engage with practitioners and researchers who:

1. are focused on health services to address both the supply side and the demand side issues in innovative ways to reach the majority of the population

2. are focused on priority setting to ensure that we think more carefully about how many lives we are losing or saving from COVID-19 in contrast to lives that could be lost by disruption of essential services

3. are able to understand both the indirect and direct effects of the pandemic on co-morbidities

4. are able to help to understand the social and psychological ramifications of the pandemic and efforts to contain it, and can engage with experts who can think about ways to use this crisis to transform health services

These individuals should not be confined to clinicians and epidemiologists; to ensure the best outcome there is a need to also engage communicators, as well as behavioural and social scientists

It is acknowledged that even in the best of times, efforts to address South Africa's quadruple disease burden is challenging. This is generated by the confluence of HIV and TB with obesity and noncommunicable diseases (NCDs), continuing poor outcomes for child and maternal mortality as well as injury and violence, all the in the context of the inequities produced by our social determinants of health. In particular, the associated loss of income as a result of the lockdown has also increased hunger, and will have an impact on malnutrition. The full extent of the potentially drastic knock-on effect of COVID-19 on these critical issues is however, not appreciated. We already know that the nation-wide lockdown has resulted in both the demand side and the supply side shifts. On the supply side, human resources shift to COVID-19 has resulted in limited services for diagnosis, treatment and prevention of other health issues. On the demand side, the public has avoided health facilities, and has been affected by transport restrictions. For example, since the beginning of the lockdown, the National Institute for Communicable Diseases (NICD) has shown a 48\% decline in testing for TB, as well as a $33 \%$ reduction in newly diagnosed positive cases over a 5-week period compared to the 6-week period preceding the level-5 lockdown ${ }^{2}$. In related data, since the beginning of the lockdown, 27 March 2020, the Gauteng Department of Health estimated that around 1,090 patients with TB, untreated HIV, and chronic conditions such as diabetes are more vulnerable to severe COVID-19. For example, COVID-19 may indirectly impact management of patients with diabetes, but more directly when diabetics are infected ensuing in poorer health outcomes. This exacerbation of the multiple-disease burden puts further strain on the national healthcare system. Not only does it have cost implications but more importantly, the human resources for delivering routine care during a pandemic, are limited ${ }^{1,3}$.

Until we have a vaccine or a cure, COVID-19 might be amongst us for a while. Finite resources cannot be diverted solely to the pandemic. Careful priority setting, taking into consideration the costs and benefits of basic health interventions and services, are critical to the success and sustainability of public health gains of the past decades, while simultaneously addressing the COVID-19 pandemic.

There is also an urgent need for transparent and explicit decision-making that takes into account the losses and gains of shifting resources and simultaneously fostering equity in the distribution of health expenditure and subsequent outcomes.

When developing guidance for the health system and weighing different options, policy makers must consider the potential effects of COVID-19 on South Africa's complex disease burden. We need to ensure the continuity of health promotion, disease prevention and treatment services in order to avert excess death from the top four conditions and to prevent increases in their incidence during and after the COVID-19 pandemic. Even if the resources at health facilities were not crowded out by focus on COVID-19, the economic impact of the pandemic, such as increased unemployment, has the potential to erode spending power of those who can no longer afford to pay their transport costs to the clinic.

Possible impacts of privileging COVID-19 on the quadruple burden of disease include the following examples:

HIV: A six-month interruption of supply of ARVs across the whole population of HIV patients on treatment in South Africa would lead to an approximately 2-fold increase in HIV-related deaths over a one-year period. This amounts to an excess of between 83,800 and 140,900 adult HIV deaths should such a high level of disruption occur ${ }^{4}$.

Maternal and child health: Disruption to maternal and child health (MNCH) services could have a similarly devastating impact. A 9\%-18\% reduction on $\mathrm{MNCH}$ coverage over a 6-month period would lead to an additional 2,160 child deaths at a minimum in South Africa ${ }^{5}$, despite children being at extremely low risk for severe COVID-19 illness. Of all $\mathrm{MNCH}$ services, sustaining routine childhood immunisation is particularly important. Measles in particular is a highly contagious disease that mostly affect children under the age of 5 years. The basic reproductive number of measles in a susceptible population is between 12 and 18; i.e. number of people that could be infected on average by every one person with measles. In contrast, while we do not know with certainty, the reproductive number of symptomatic cases of SARS-CoV-2 is thought to be approximately $2.5^{6}$. Previous South African research in 2010 shows what can happen when health workers are diverted to focus on a single issue - in this case a catch-up campaign for measles. In 2010, over this same three week period in 52 districts there was a $30 \%$ decrease in children completing the primary course of immunisation, a $10 \%$ decrease in antenatal visits and a $12 \%-17 \%$ decrease in use of injectable contraceptives ${ }^{7}$

Non-communicable diseases: South Africa has high rates of type 2 diabetes $(12 \%)$, obesity and overweight $(68 \%$ of women and $31 \%$ of men age $15+)$, and hypertension $(35 \%)^{8}$, which may actually be

\section{HOW TO CITE:}


underestimates of the burden of these co-morbidities ${ }^{9,10}$. Control of these NCDs is critical since individuals with these co-morbidities are at greater risk for severe COVID-19 illness and death ${ }^{11}$. Any pandemic response needs to ensure that disruption to routine medical appointments and tests are minimised to prevent interruptions in NCD management and continuity of care.

Violence and injury: During the original lockdown, with alcohol sales restrictions, trauma admissions and motor vehicle injuries were reduced. Subsequently and following the opening of alcohol sales there has been a surge of both intentional and unintentional harm. At the same time, officially reported cases of gender-based violence (GBV) seemed to decrease, the number of GBV distress calls increased from 12,000 to almost 80,000 by week three of the lockdown ${ }^{12}$, suggesting that women could not access services. A 2014 study estimated that GBV, and in particular violence against women, costs the South African economy a minimum of between R28.4 billion and R42.4 billion per annum, or between $0.9 \%$ and $1.3 \%$ of gross domestic product (GDP) in the year $2012 / 2013^{13}$. A loss of focus on the fight against GBV during the pandemic will be extremely detrimental for women and children.

\section{In Summary:}

The COVID-19 pandemic has revealed pre-existing weaknesses in our healthcare system that have been exacerbated. Efficient and equitable allocation of resources are thus critical now more than ever. Unless we prioritise interventions that that are cost-effective and address the major challenges from both the demand side and the supply side, South Africa will experience increased mortality and morbidity from diseases that have been side-lined in favour of COVID-19. This outcome will obliterate hard-won improvements in life expectancy over the past decade, thwarting any chance of South Africa reaching its SDG 2030 targets. To avert this scenario, the ASSAf Standing Committee on Health urges the National Department of Health:

1. to engage a broad-spectrum of stakeholders without delay

2. to request evidence of the potential trade-offs and the consequent resource implications and

3. to promote a coordinated and collaborative funded research programme that encompasses multiple disciplines for both understanding the health burden complexity and for breakthrough innovations in public health and healthcare

\section{Authors in alphabetical order (ASSAf Standing Committee on Health Members):}

Prof John Ataguba, Prof Olalekan Ayo-Yusuf, Prof Minrie Greeff, Prof Karen Hofman, Dr Elizabeth Lutge, Prof Shabir Madhi, Prof Angela Mathee, Prof Neil McKerrow, Prof Mosa Moshabela, Prof Shane Norris, Prof Solomon Rataemane, Prof Steve Reid, Prof Linda Richter, Prof Heidi van Rooyen, and Dr Caradee Wright

\section{Issued:}

3 July 2020

\section{References:}

1. Steyn D. Covid-19: SA's TB response has already been affected [Internet]. CityPress. 2020 [cited 2020 May 24]. Available from: https://city-press.news24. com/News/covid-19-sas-tb-response-has-already-been-affected-20200427
2. NICD. Impact of COVID-19 intervention on TB testing in South Africa [Internet]. 2020 May [cited 2020 Jun 3]. Available from: https://www.nicd. ac.za/wp-content/uploads/2020/05/Impact-of-Covid-19-interventions-onTB-testing-in-South-Africa-10-May-2020.pdf

3. Almost 11,000 HIV-positive patients in Gauteng have skipped ARV collection during lockdown [Internet]. SowetanLIVE. [cited 2020 May 24]. Available from: https://www.sowetanlive.co.za/news/south-africa/2020-05-19-almost11000-hiv-positive-patients-in-gauteng-have-skipped-arv-collection-duringlockdown/

4. Jewell BL, Mudimu E, Stover J, Kelly SL, Phillips A. Potential effects of disruption to HIV programmes in sub-Saharan Africa caused by COVID-19: results from multiple mathematical models [Internet]. 2020 [cited 2020 May 23]. Available from: https://figshare.com/articles/Potential effects of disruption to HIV programmes_in_sub-Saharan_Africa_caused_by_COVIID-19_results_from_ multiple_mathematical_models/12279̄914

5. Roberton T, Carter ED, Chou VB, Stegmuller AR, Jackson BD, Tam Y, et al Early estimates of the indirect effects of the COVID-19 pandemic on maternal and child mortality in low-income and middle-income countries: a modelling study. The Lancet Global Health [Internet]. 2020;8:e901-080. https://doi. org/10.1016/S2214-109X(20)30229-1

6. Lai C-C, Shih T-P, Ko W-C, Tang H-J, Hsueh P-R. Severe acute respiratory syndrome coronavirus 2 (SARS-CoV-2) and coronavirus disease-2019 (COVID-19): The epidemic and the challenges. International Journal of Antimicrobial Agents. 2020 Mar 1;55(3):105924. https://doi.org/10.1016/j. ijantimicag.2020.105924

7. Verguet S, Jassat W, Bertram MY, Tollman SM, Murray CJL, Jamison DT, et al. Supplementary immunization activities (SIAs) in South Africa: comprehensive economic evaluation of an integrated child health delivery platform. Glob Health Action [Internet]. 2013 Mar 1 [cited 2020 Jun 3];6. Available from: https://www.ncbi.nlm.nih.gov/pmc/articles/PMC3587392/

8. South Africa Demographic and Health Survey 2016 [Internet]. Pretoria: National Department of Health, Statistics. Statistics South Africa; 2017 [cited 2017 Nov 8]. Available from: http://www.mrc.ac.za/bod/SADHS2016.pdf

9. Stokes A, Berry KM, Mchiza Z, Parker W, Labadarios D, Chola L, et al. Prevalence and unmet need for diabetes care across the care continuum in a national sample of South African adults: Evidence from the SANHANES-1, 2011-2012. PLoS ONE. 2017 Oct 2;12(10):e0184264. https://doi.org/10.1371/journal. pone. 0184264

10. Berry KM, Parker W, Mchiza ZJ, Sewpaul R, Labadarios D, Rosen S, et al. Quantifying unmet need for hypertension care in South Africa through a care cascade: evidence from the SANHANES, 2011-2012. BMJ Glob Health [Internet]. 2017 Aug 16 [cited 2020 May 25];2(3). Available from: https:// www.ncbi.nlm.nih.gov/pmc/articles/PMC5656122/

11. Kluge HHP, Wickramasinghe K, Rippin HL, Mendes R, Peters DH, Kontsevaya A et al. Prevention and control of non-communicable diseases in the COVID-19 response. The Lancet [Internet]. 2020 May 8 [cited 2020 May 23];0(0). Available from: https://www.thelancet.com/journals/lancet/article/PIIS0140 6736(20)31067-9/abstract

12. Gender-based violence cases rose by $500 \%$ since start of lockdown Lifeline [Internet]. [cited 2020 May 25]. Available from: https://www.iol. co.za/the-star/news/gender-based-violence-cases-rose-by-500-sincestart-of-lockdown-lifeline-48193496

13. Bafana Khumalo, Sisonke Msimang, Katie Bollbach. Too Costly to Ignore The Economic Impact of Gender-Based Violence in South Africa [Internet]. Johannesburg: KPMG Human and Social Services; 2014 [cited 2020 May 25]. Available from: http://www.ci.uct.ac.za/overview-violence/reports/toocostly-to-ignore-the-economic-impact-of-GBV-in-SA 